\title{
APPRAISING THE STRONGLY ASSOCIATED IMPACTS TO CHOOSE THE MODE OF PUBLIC TRANSPORT: A CASE STUDY OF COLOMBO METROPOLITAN AREA IN SRI LANKA
}

\author{
Manjula Madhuwanthi ${ }^{1}$, Ashuboda Marasinghe ${ }^{2}$, Shusaku Nomura ${ }^{3}$ \\ 1, 2, 3 Department of Information Science and Control Engineering, Graduate School of Engineering - \\ Doctoral Program, Nagaoka University of Technology, Nagaoka, 940-2137, Japan
}

Received 17 August 2015; accepted 29 January 2016

\begin{abstract}
This study examines a model to evaluate the probability of choosing the mode of public transport with finding most significant aspects related to the characteristic of the journey, characteristic of the traveler and the personal behavior of the traveler. The study area was focused on eleven Divisional Secretariat Divisions of the Colombo Metropolitan Area in the Western Province of Sri Lanka. This area has the most economically advanced functions as the commercial capital of Sri Lanka. The current transportation sector in the focusing area has impact of increasing vehicle ownership and serious inadequacies in the road network such as traffic congestions, shortfall of road capacity and low speed level on road. Hence this study attempts to encourage people for the public transport by focusing about their perception related to the mode choice as a solution for the above issues. The results showed that "Number of Earning Members", "Vehicle Ownership", "Education", "Age”, "Gender”, “Occupation”, “Trip Distance., "Trip Time”, "Total Cost” and "Safety” of the mode were the most significant factors for affecting to choose the public transport. The obtained logistic model with the significant variables had the $78.4 \%$ of accuracy for the prediction of probability in using public transport.
\end{abstract}

Keywords: significant factors, mode choice, logistic regression, public transport.

\section{Introduction}

Traffic congestion is a one of main problems associated with increasing the risk of road accidents in the urban areas (Lalitha and Ruther, 2014). Road traffic crashes rank as the $9^{\text {th }}$ leading cause of death and account for $2.2 \%$ of all deaths globally (Mohanty and Gupta, 2015). A more interesting thing is that a greater use of private vehicle on roads is to increase the traffic congestion on roads (Annan et al., 2015). As well as the "poor quality of public transport contributes to increase market share of private motorized traffic, which in turn leads to increase congestion" (Rasario, 2011). On the other hand, there is a direct relationship between the ridership on public transport and the usage of private vehicle (Thomas and Adam, 2012). Because there are several reasons that taken place to use of private vehicles without using the public transport such as unreliability and the low quality of the public transport. With this situation, the traffic congestion is increased due to the greater use of private vehicles without using public transport.

However public transport service is an effective solution for the traffic congestion in the urban areas (Zhang and Yue, 2001).

\footnotetext{
${ }^{1}$ Corresponding author: s147004@stn.nagaokaut.ac.jp
} 
Also another research shows that "A wellperforming public transport system provides a credible alternative to drive for many trips in a metropolitan region, and therefore has the potential to mitigate road traffic, alleviate auto dependency, and reduce greenhouse gas emissions" (Guo, 2008). Additionally to that, shifting from private to public transportation can have numerous advantages such as reduction in energy consumption, ensures safety, save in money, improve air quality and even fosters more livable communities (Jaiswal and Sharma, 2012).

As above-mentioned, the public transport is vital, encouraging people for the public transport is an essential requirement for the economic development as well as for the reduction in traffic congestion and the road accidents. According to the previous researchers, "reliability of public transport systems has been considered critically important by most public transport users because passengers are adversely affected by the consequences associated with unreliability such as additional waiting time, late or early arrival at destinations and missed connections, which increases their anxiety and discomfort" (van Oort, 2011). Further, preventing any unexpected event (injuries, theft and others) comes from personal responsibility. By taking responsibility on other commutes, accidents can generally be prevented. The travelers play the main role in encouraging people to behave in a safe manner (Rundmo et al., 2011). Hence the travel behavior of the people and their perceptions regarding the public transportation are essential to analyze for the development of public transport (Jolly et al., 2006). Thus, these findings understand the important of the identification about the traveler perception of the mode choice to increase the development of public transport. Understanding mode choice is important since it affects how efficiently we can travel, how much urban space is devoted to transportation functions as well as the range of alternatives available to the traveler (Ortuzar and Willumsen, 1994).

The public transportation sector in Sri Lanka suffers from many deficiencies due to the lack of effective and consistent policy to guide the sector (Kumarage, 2002). According to Sevanatha Urban Resource Center in Sri Lanka (2002), a majority of the respondents in the city of Colombo spend more time for their travel than normally expected to reach their destinations and they are facing problem while travelling which result in delaying their journeys and then loss of time and money. Over $50 \%$ of the respondents seem to have been unhappy about the mode of public transport and condition of transport operated in the city they use for their daily travel. On the other hand the trip demand and private vehicle usage of the Colombo Metropolitan Area (CMA) in the western province of Sri Lanka are increasing rapidly (JICA, 2014). Fig. 1 and Fig. 2 illustrate that the total person trip demand would increase by 1.75 times from 2013 to 2035 however it should be noted that the trip made by private car would increase from 0.93 million trips in 2013 to 5.55 million trips in 2035, which implies that the growth of trips by cars accounts for almost six times of the increase during the period. Because of these negative perceptions of the travelers, the CMA in Sri Lanka was focused as the study area. As well as roughly half of the country's economic activities are concentrated in this area and the nation's largest international seaports and the airports are located within the area too (JICA, 2014). Hence the development of this area is vital and it will be directly affect to the economic development of the Country. 


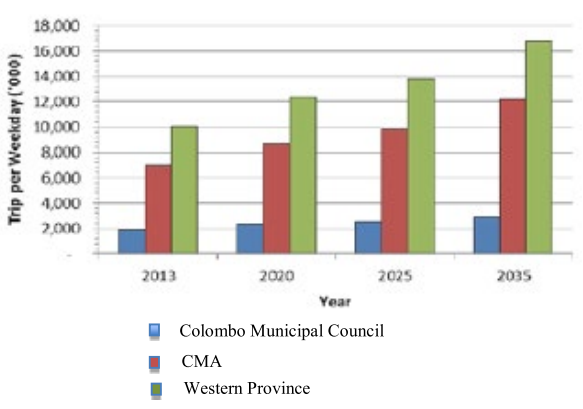

Fig. 1.

Increase of Person Trip Demand by Region Source: JICA (2014)

The objective of this study was to evaluate the probability of choosing the mode of public transport with finding a model by most significant aspects related to the traveler's selection of public transport. With considering about previous emerging researches related to the analysis of mode choice behavior of the travelers, most of the studies have been focused on one regular trip for their analysis and/ or considered about one particular subject for their analysis. For instance, Mohammed and Shakir (2013) focus to the factors influencing to select the transportation modes by university students. Dill and Wardell (1994) evaluate the factors affecting only for worksite mode choice. Su et al. (2009) find the mode choice of older people before and after shopping. However this study attempted to evaluate the travel behavior of the subject who belongs to a particular household. The households were selected by randomly in the selected area and their regular travel activities were considered for the evaluation rather without concerning only one particular categorized subject or a particular trip. All the members who were greater than fifteen years old of that household were evaluated as it was a best way to identify the regular lifestyle of

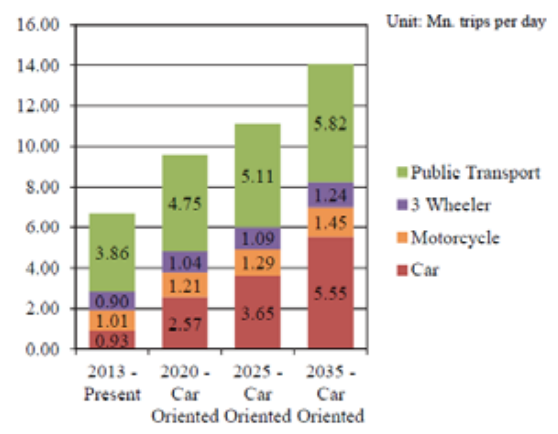

Fig. 2.

Increase of Person Trips by Mode of Transport Source: JICA (2014)

that household in a specified area. Not only that, but also the difference of this study compares to the other related studies was the evaluation methodology.

\section{Methodology}

The overall process of the study is illustrated in Fig. 3. The very first step of this study was the problem identification related to the transportation sector and it was identified that people were unhappy and unsatisfied about the mode of public transport in CMA of Sri Lanka (JICA, 2014). One of the main reasons was the high traffic congestion in that area due to the high trip demand made by private vehicles. Thus this study was motivated to examine the people's perception regarding the mode choice of public transport to encourage for the usage of public transport rather using private vehicles. And also it will be aid to reduce the traffic congestion and to develop the economic situation in the area as this area contributes to the country with most economical activities. Then the next step was to create the objective related to the problem with determining a model to illuminate the probability of choosing the mode of public transport by concerning 
the strongly associated criteria related to the traveler perception. As the third step, the criteria of the evaluation were made by concerning the traveler perception with regarding the characteristic of Fig. 4. The next step was to design the questionnaire with including the chosen criteria while conducting a pilot test for the selected subjects in the area for a better solution. After doing several corrections with the sampled subjects, the questionnaire was finalized and confirmed to deliver to the public in the selected area. Then the next step was to collect the date within couple of months and the collected data was sorted and prepared for the analysis. Then the obtained data was analyzed with binary logistic method to find the model of mode choice. The logistic model was developed after several steps as revealed in the analysis part of the Fig. 3. Finally, the evaluation process was completed by interpreting the model with giving a number of recommendations to the responsible policy makers.

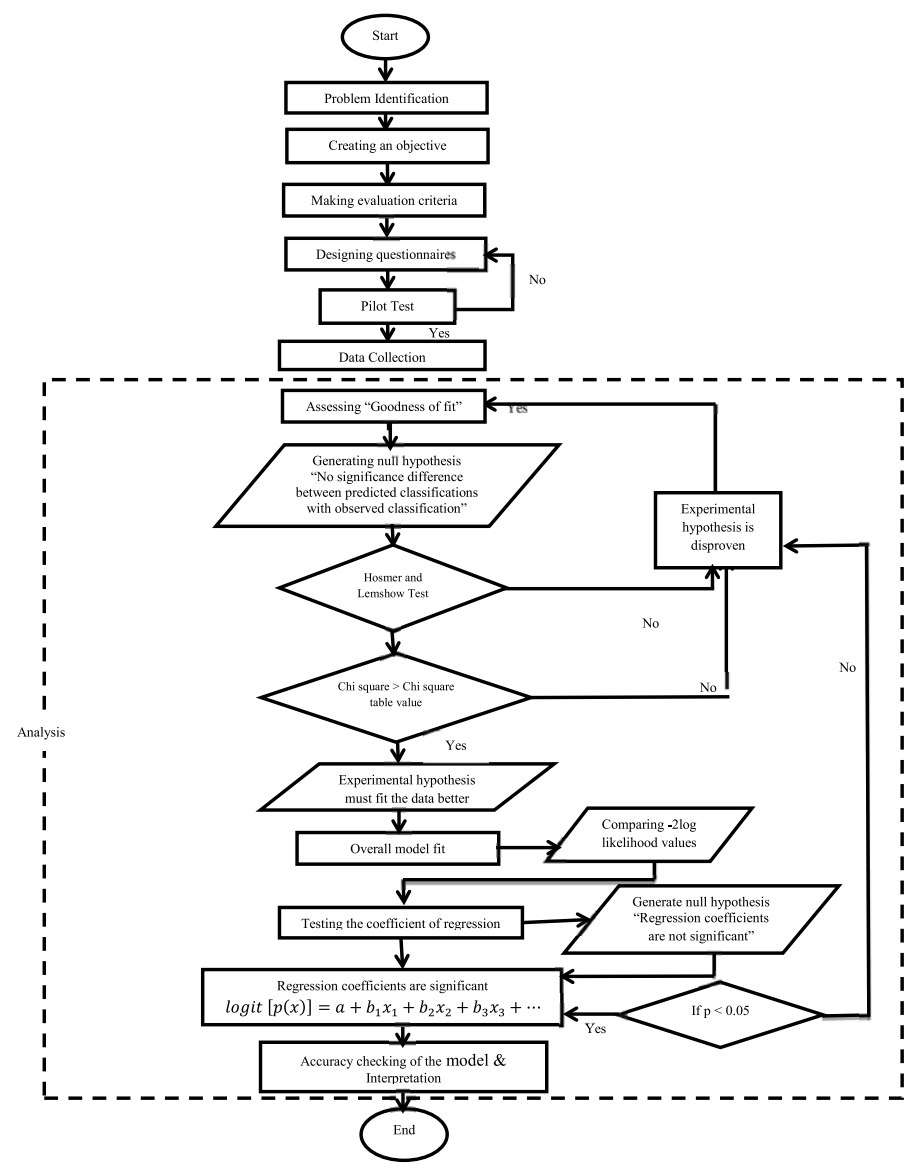

Fig. 3.

Flow Chart of the Study 


\subsection{Study Area}

Colombo Metropolitan Area is the largest metropolitan area in Sri Lanka. It consists 20 Divisional Secretariat Divisions (DSD) which are included to three districts, Colombo, Gampaha and Kalutara. The population of CMA was 3.7 million inhabitants in 2012. It is estimated that the total population of CMA will increase to 5.1 million people in 2035 (JICA, 2014). This study focused on 11 DSDs, which are included only to Colombo District in CMA since only these DSDs are covered the $57.8 \%$ of population from CMA and commercial and the residential activities are high rather from the other 9 DSDS. And also, according to our previous studies, only these 11 DSDs are recommended for the implementation of Activity Based Travel Demand models
(Madhuwanthi et al., 2015). Therefore, this study focused on these 11 DSDs for the analysis.

\subsection{Data Collection}

The subjects of this study were selected randomly and belonged to the all types of class residents with emphasis their regular travel patterns. Every members of the family who were greater than fifteen years old that considered with regarding the categories in Fig. 4. The data were collected from a pre-formatted questionnaire. There were 422 residents that responded and out of that sample population, 48 respondents (10.9\%) were not making any trips. Remaining 374 respondents (89.1\%) made on their regular trips for the purpose of work, education, business, shopping or recreational activities.

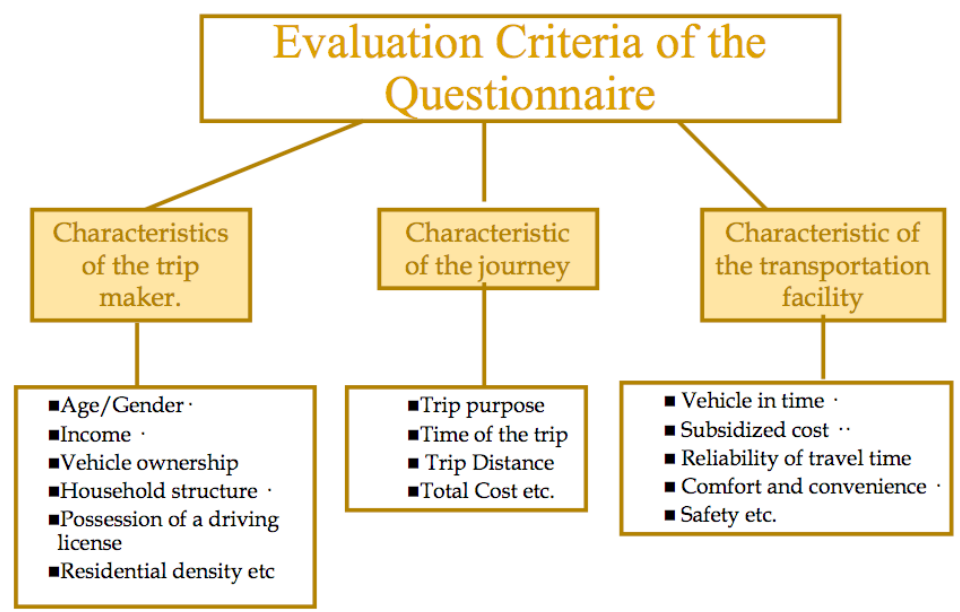

Fig. 4.

Evaluation Criteria of the Questionnaire

\subsection{Data Analysis}

The data obtained from the travel maker were analyzed by using binary logistic regression. Logistic regression can be used to find the strongly associated variables with the probability of a particular category in another variable occurring (Cramer, 2003). 
Logistic regression determines the impact of multiple independent variables $X_{1}, X_{2}, X_{3}$, ..., $X_{k}$ presented simultaneously to predict membership of one or other of two depended $Y$ variable categories. The software SPSS was used to estimate the model through maximum likelihood function. The procedure to analysis the probability of choosing the mode of public transport by using this logistic regression is illustrated in Fig. 3.

\subsection{Parameter Estimation}

Logistic regression was applied to determine the relationship between most significant factors related to the mode choice of public transport with the categories of Fig. 4. The subjects who selected the public transport were coded as 1 while those who selected the private transport were coded as 0 . The outcome is not a prediction of a $Y$ depended value, as in linear regression, but a probability of belonging to one of two conditions of $Y$.

The log transformation of the $P$ (probability) values to a log distribution enables to create a link with the normal regression equation as follows.

$\operatorname{logit}(p)=\log \left[\frac{p}{(1-p)}\right]$

Where;

$p=$ probability

$\operatorname{logit}(p)=\log ($ base $e)$ at the odds ratio or likelihood ratio.

The following Eq. (2) shows the relationship between the usual regression equation and the logistic regression equation.

$\operatorname{logit}[p(x)]=\log \left[\frac{p(x)}{(1-p(x))}\right]=a+b_{1} x_{1}+b_{2} x_{2}+b_{3} x_{3}+\cdots$
Then the $p$ can be calculated by using the following Eq. (3):

$p=\frac{\exp ^{\left(a+b_{1} x_{1}+b_{2} x_{2}+b_{3} x_{3}+\cdots\right)}}{1+\exp ^{\left(a+b_{1} x_{1}+b_{2} x_{2}+b_{3} x_{3}+\cdots\right)}}$

Where:

$p=$ the probability that choosing a mode of public transport

$\exp =$ the base of natural logarithms (approx 2.72)

$a=$ the constant of the equation and $b=$ the coefficient of the predictor variables related to the travel maker.

This uses a maximum likelihood method, which maximizes the probability of getting the observed results given in the fitted regression coefficient (Elkan, 2014).

\subsection{Feasibility of the Model}

Hosmer and Lemshow test values which is similar to chi-square test can be used to find weather the model is well- fitting or not. The well-fitting models show nonsignificance on the goodness of fit test. It implies that the model prediction that is not significantly different from observed values. The hypothesis can be generated as follows.

$\mathrm{H}_{0}$ : There are no significant differences between predicted classifications with observed classification

$\mathrm{H}_{1}$ : There are significant differences between predicted classifications with observed classification

\section{Table 1}

Hosmer and Lemshow Test

\begin{tabular}{|l|l|l|l|}
\hline Step & Chi-square & df & Sig. \\
\hline 1 & 10.141 & 8 & 0.255 \\
\hline
\end{tabular}


The significant values of the Table 1 is 0.255 , which is greater than 0.05 . It indicates that $\mathrm{H}_{0}$ is accepted and there are no significant differences between predicted classifications with observed classification. This result suggests that the binary logistic regression for mode choice is feasible to be used for further analysis. The chi-square value of the table is 10.141 which is less than the table values of 15.5073 ( $d f=8$ and 0.05 level). According to this chi-square value is also implied that the $\mathrm{H}_{0}$ is accepted and the model related to mode choice is feasible to be further analysis.

\subsection{Measuring the Overall Model Fit}

To determine whether the model is statistically significant or not, log-likelihood ratio test is conducted by comparing the Log Likelihood (LL) function of the estimated model to that of the LL function of base model (Subbarao and Krishna Rao, 2013). The likelihood ratio test is based on -2LL ratio. It is a test of the significance of the difference between the likelihood ratio (-2LL) for the researcher's model with predictors (called model chi square) minus the likelihood ratio for baseline model with only a constant in it.

Table 2

Iteration History (Block 0: Beginning Block)

\begin{tabular}{|l|c|l|l|}
\hline \multirow{2}{*}{ Iteration } & \multirow{2}{*}{-2 Log likelihood } & Coefficients \\
\cline { 3 - 4 } Step 0 & 1 & 514.313 & Constant \\
\cline { 2 - 4 } & 2 & 514.313 & 0.005 \\
\hline
\end{tabular}

Table 3

Model Summary (Block 1: Method = Enter $)$

\begin{tabular}{|l|l|l|l|}
\hline Step & -2 Log likelihood & Cox \& Snell R Square & Nagelkerke R Square \\
\hline 1 & 348.134 & 0.361 & 0.481 \\
\hline
\end{tabular}

The score of $-2 \log$ likelihood is 514.313 in the Table 2 (Block 0) and the same score in Table 3 (Block 1 ) is 348.134 . The decreasing of that value illustrates that the mode choice regression model is a better model since the Likelihood of the Binary Logistic similar with the definition of 'sum of squared error' in regression model.

\section{Results and Discussion}

Table 4 depicts the Wald statistic and associated probabilities provide an index of the significance of each predictor in the mode choice equation. The Wald statistic has a chi-square distribution (Williams, 2015).
There were 21 variables that considered for the model. The variables related to the travel maker that have the value of less than 0.05 under the column of significant were considered for the equation. The 11 variables out of 21 variables were needed to drop independents from the mode choice model when their effect was not significant by the Wald statistic. The Exp (B) column in the table presents the extent to which raising the corresponding measure by oneunit influences the odds ratio. The ' $B$ ' values are the logistic coefficients that can be used to create a predictive equation. According to the table, the selected variables are the significant variables for the model. 


\section{Table 4}

Variables in the Equation

\begin{tabular}{|l|l|l|l|l|l|l|}
\hline Variables & B & S.E. & Wald & df & Sig. & Exp (B) \\
\hline Family Income $\left(\mathrm{X}_{1}\right)$ & -0.213 & 0.132 & 2.585 & 1 & 0.108 & 0.808 \\
Residence Type $\left(\mathrm{X}_{2}\right)$ & 0.036 & 0.222 & 0.027 & 1 & 0.870 & 1.037 \\
Household Size $\left(\mathrm{X}_{3}\right)$ & -0.120 & 0.147 & 0.672 & 1 & 0.412 & 0.887 \\
Earning Members $\left(\mathrm{X}_{4}\right)$ & 0.532 & 0.212 & 6.308 & 1 & 0.012 & 1.702 \\
Vehicle Ownership $\left(\mathrm{X}_{5}\right)$ & -0.716 & 0.128 & 31.421 & 1 & 0.000 & 0.489 \\
Gender $\left(\mathrm{X}_{6}\right)$ & -1.07 & 0.346 & 9.607 & 1 & 0.002 & 0.343 \\
Age $\left(\mathrm{X}_{7}\right)$ & 0.252 & 0.124 & 4.145 & 1 & 0.042 & 1.287 \\
Education $\left(\mathrm{X}_{8}\right)$ & 0.414 & 0.179 & 5.354 & 1 & 0.021 & 1.512 \\
Occupation $\left(\mathrm{X}_{9}\right)$ & -0.552 & 0.134 & 16.879 & 1 & 0.000 & 0.576 \\
License Holder $\left(\mathrm{X}_{10}\right)$ & -0.625 & 0.447 & 1.954 & 1 & 0.162 & 0.535 \\
Trip Purpose $\left(\mathrm{X}_{11}\right)$ & 0.005 & 0.131 & 0.001 & 1 & 0.970 & 1.005 \\
Trip Distance $\left(\mathrm{X}_{12}\right)$ & 0.520 & 0.154 & 11.430 & 1 & 0.001 & 1.683 \\
Trip Time $\left(\mathrm{X}_{13}\right)$ & 0.643 & 0.178 & 13.074 & 1 & 0.000 & 1.901 \\
Total Cost $\left(\mathrm{X}_{14}\right)$ & -0.985 & 0.208 & 22.358 & 1 & 0.000 & 0.373 \\
Waiting Time $\left(\mathrm{X}_{15}\right)$ & -0.216 & 0.171 & 1.591 & 1 & 0.207 & 0.806 \\
Vehicle Travel Time $\left(\mathrm{X}_{16}\right)\left(\mathrm{X}_{1}\right)$ & 0.155 & 0.241 & 0.412 & 1 & 0.521 & 1.167 \\
Subsidized Cost $\left(\mathrm{X}_{17}\right)$ & 0.160 & 0.229 & 0.487 & 1 & 0.485 & 1.174 \\
Access Time $\left(\mathrm{X}_{18}\right)$ & 0.242 & 0.227 & 1.140 & 1 & 0.286 & 1.274 \\
Comfort $\left(\mathrm{X}_{19}\right)$ & 0.198 & 0.153 & 1.670 & 1 & 0.196 & 1.219 \\
Safety $\left(\mathrm{X}_{20}\right)$ & -0.773 & 0.204 & 14.444 & 1 & 0.000 & 0.461 \\
Time Reliability $\left(\mathrm{X}_{21}\right)$ & -0.035 & 0.225 & 0.024 & 1 & 0.877 & 0.966 \\
Constant & 3.01 & 2.00 & 2.262 & 1 & 0.133 & 20.404 \\
\hline
\end{tabular}

The predictive equation can be written with the 10 significant variables, which the significant values are less than 0.05 . From the Table 4, the ' $\mathrm{B}$ ' values are the logistic coefficients that can be used to create the mode choice equation.

$$
\begin{aligned}
& \operatorname{logit}[P(X)]=\log \left[\frac{P(X)}{(1-P(X))}\right] \\
& \text { logit }[P(X)]=3.01+0.532 X_{4}-0.716 X_{5}-1.071 X_{6}+0.252 X_{7}+0.414 X_{8}-0.552 X_{9}+0.520 X_{12}+0.643 X_{13} \\
& -0.985 X_{14}-0.773 X_{20}
\end{aligned}
$$

The people who are living at Colombo area within the CMA, considered about ten significant factors related to the choice of public transport since the Table 4 verifies the values. Earning members $\left(\mathrm{X}_{4}\right)$, Vehicle Ownership $\left(X_{5}\right)$, Gender $\left(X_{6}\right)$, Age $\left(X_{7}\right)$, Education $\left(\mathrm{X}_{8}\right)$, Occupation $\left(\mathrm{X}_{9}\right)$, Trip Distance $\left(\mathrm{X}_{12}\right)$, Trip Time $\left(\mathrm{X}_{13}\right)$, Total Cost
$\left(\mathrm{X}_{14}\right)$ and safety $\left(\mathrm{X}_{20}\right)$ were the factors that the people mostly consider about the public transport.

- The significant value for the variable $\left(\mathrm{X}_{4}\right)$ of "Earning Members" was 0.012 and it implies that there is a significant influence from the number of earning members 
of a household for the decision of using public transport. The Odds probability to use public transport as much of affecting value was $\operatorname{Exp}(B)=1.702$. According to the questionnaire survey, even the households that had large number of earning members (more than $3)$, they mostly used the public transport. Even though that household with public transport users had large number of earning members, the majority of their income level was low to middle level (Sri Lankan Rupees 15,000-75000, 54.8\%). Hence this type of households had not enough financial situation to grab their own vehicle even their family included a large number of earning members. Occasionally though a particular household had a greater number of members with a private vehicle, the workers of that household tended to use public transport with offering private automobiles to the other members of the family. On the other hand the small size household did not have enough financial situations to go for a private automobile and therefore less likely to own an automobile and use the public transport.

- The significant value for the variable $\left(\mathrm{X}_{5}\right)$ of "Vehicle Ownership" was 0.00 . It means the factor vehicle ownership was highly affected to the decision of public transport. The people who had an own vehicle, they did not use the public transport. The minus sign for the $B$ value interpreted that if the people have their own vehicle it will decrease the odds probability to use public transport as much $\operatorname{Exp}(B)=0.489$.

- The variable $\left(\mathrm{X}_{6}\right)$ "Gender" was also a considerable factor for the selection of public transport. The survey results showed that the female travelers had a greater choice to use the public transport than the male users. It is clear that the most of the females in Sri Lanka are not the vehicle license holders and vehicle owners. Therefore the females tend to use public transport than the male travelers. The variable of gender was affected for the choice of public transport with the value of $\operatorname{Exp}(B)=0.343$.

The next imperative variables were the "Age" $\left(\mathrm{X}_{7}\right)$, "Education" $\left(\mathrm{X}_{8}\right)$ and "Occupation" $\left(\mathrm{X}_{9}\right)$ as those significant values were less than 0.05 . According to the survey conducted, the young people (age between 15-30 years old) used public transport for their regular trips. Most of these young people made their trip purpose for the education and yet they depended with their parents or others and did not have their own profession. Hence they did not have their own vehicles and then tended to the public transport. With concerning the variable of "Education", the people who had a low educational level, did not a considerable income level and an occupation. Those people also tended to use the public transport without using private vehicles for their regular trip purpose. If a person had a decent occupation with high level of salary scale, they did not make their trip by public transport. They wished to go for a private transport since they think about their goodwill, privacy and their comfort. That was the reason to get a minus value for the $B$ value of the variable of "Occupation". On the other hand, the gap between the rich-poor is wide in Sri Lanka (Hiyal, 2013) and thus the people who have a considerable education level and an occupation, they try to use their own vehicle without using public transport as 
the people think that the public transport is for only the poor people.

- The significant values for the variables of “Trip Distance" $\left(\mathrm{X}_{12}\right)$, “Trip Time” $\left(\mathrm{X}_{13}\right)$ and "Total Cost" $\left(\mathrm{X}_{14}\right)$ were less than 0.05 and it illustrates that those variables highly affected to the decision of getting public transport. The decision for the factors of trip distance, trip time and the total cost were very important for the people's regular trips. If the destination was so far from the home and the trip was getting too much time, the people tended to select the public transport as the people regularly do not like to ride their own vehicles for a long time and so far to the destination of the regular trips. However, if the total cost for the regular trips was too much high, then the people considered about the mode and compared the benefits of each. When the cost was high in public transport, it is possible to get the private mode for the travel as usually the people believe that the comfort and the cleanliness are lack in the public transport. The Odds probability to use public transport as much of affecting value was $\operatorname{Exp}(B)=0.373$.

- Next significant factor was "Safety" $\left(\mathrm{X}_{20}\right)$ with the value of 0.00 . It indicates that the safety is very important factor for the travelers. But the B value (-0.773) was negative and it illustrates that the people argued the safety and the security of the public transport was lack in Sri Lanka. Thus they did not have trustworthiness about the public transport with the aspect of safety and the security. Most public transport is involved in more than 50\% of all accidents and driver behavior that may be contributing to a high incidence of their involvement in road accidents (Sunday Times, 2001). But most of the people used the public transport due to their low income situation. The people, who are living in developing countries like Sri Lanka, tend to use public transport as their low income and are not the vehicle owners. Even the public transport had low safety and security, people used the public transport due to the low income levels.

\subsection{Accuracy of the Model}

The accuracy of the model can be measure by comparing predicted values from the dependent variables and the actual observed data value. In this Table 5, the cut off value is 0.5 implies that the probability value more than or equal with 0.5 means the probability tendency will go to public transport, while if the probability value is less than 0.5 it means the probability will go to private transport. According to the table, the overall percentage was $78.4 \%$. It indicates that the accuracy of the model was $78.4 \%$ and the model can be predicted with this much of accuracy.

\section{Table 5}

Classification Table ${ }^{a}$

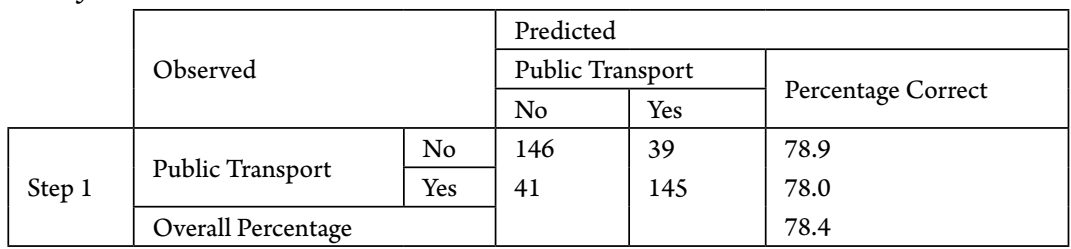

a. The cut off value is 0.5 
As a result of this model, the people of the selected area can be categorized that he/she has this much of probability tendency for the usage of public transport. For instance, if a particular male person in the area had 3 number of earning members of his household and he was in the age category of 46-55 years and a government employee. He was included to the education level of diploma and an owner of a motorcycle. For his regular work trip, he had to spend a time around 30 minutes to 1 hour and the trip distance was 6 to $10 \mathrm{Km}$. His perception about the total cost was important while safety was very important when he traveled for his regular trip purposes. Hence, according to the model, it can be found that how much his possibility to use public transport for his regular trips. Table 6 indicates the categories and the relevant category number for each of the selected above person.

Table 6

Example: A Particular Person's Details and the Relevant Categorical Numbers

\begin{tabular}{|l|l|l|}
\cline { 2 - 3 } \multicolumn{1}{c|}{} & Category & Categorical Number \\
\hline No. of Earning Members $\left(\mathrm{x}_{4}\right)$ & 3 & 3 \\
\hline Vehicle Ownership $\left(\mathrm{x}_{5}\right)$ & Motor Cycle & 3 \\
\hline Gender $\left(\mathrm{x}_{6}\right)$ & Male & 1 \\
\hline Age $\left(\mathrm{x}_{7}\right)$ & $46-55$ years & 6 \\
\hline Education $\left(\mathrm{x}_{8}\right)$ & Diploma & 3 \\
\hline Occupation $\left(\mathrm{x}_{9}\right)$ & Gvt. Employee & 2 \\
\hline Trip Distance $\left(\mathrm{x}_{12}\right)$ & 6 -10 Km & 4 \\
\hline Trip Time $\left(\mathrm{x}_{13}\right)$ & 30 min-1 hour & 3 \\
\hline Total Cost $\left(\mathrm{x}_{14}\right)$ & Important & 3 \\
\hline Safety $\left(\mathrm{x}_{20}\right)$ & Very Important & 4 \\
\hline
\end{tabular}

Odds Probability $=\mathrm{P}(\mathrm{X})=3.016+0.532 \mathrm{X}_{4}-0.716 \mathrm{X}_{5}-1.071 \mathrm{X}_{6}+0.252 \mathrm{X}_{7}+0.414 \mathrm{X}_{8}-$ $0.552 X_{9}+0.520 \mathrm{X}_{12}+0.643 \mathrm{X}_{13}-0.985 \mathrm{X} 14-0.773 \mathrm{X} 20$

Odds Probability $=\mathrm{P}(\mathrm{X})=3.01+0.532 *(3)-0.716 *(3)-1.071 *(1)+0.252 *(6)+0.414 *(3)$ $-0.552 *(2)+0.520 *(4)+0.643 *(3)-0.985 *(3)-0.773 *(4)$ $=1.005$

Probability $=\exp (\beta 0+\beta 1+\beta 2+\beta 3+\beta 4) /(1+\exp (\beta 0+\beta 1+\beta 2+\beta 3+\beta 4))$

$$
=\exp (1.005) /(1+\exp (1.005))
$$

$=0.73$

This implies that the person which above category will tend to choose public transport of the $73 \%$ rather than private vehicle since the $p$ value is greater than 0.05 . 


\section{Conclusion and Recommendation}

The objective of this study was to design a model to evaluate the probability of selecting the mode of public transport with finding most significant aspects related to the traveler's point of view of the public transport with the intention of encouraging people for the usage of public transport. The motivation factor of this study was the increment of private vehicle on road of the selected region, Colombo Metropolitan Area in Sri Lanka. It was suggested to find the most significant factors related to the behavior of the trip maker with the aspects of the characteristics of trip maker, characteristic of the journey and characteristic of the transportation facility with related to the selected modes by using the method of Logistic Regression. The analysis has found that, 10 variables out of 21 variables were significantly affected to the model design. Number of earning members in the household, Vehicle ownership, Gender, Age, Education, Occupation, Trip Distance, Trip Time, Total Cost and Safety were the significant factors that mostly affected to the mode choice of public transport with the $78.4 \%$ of model accuracy. This model is a better model as the sum of squared error or the Likelihood of the Binary Logistic value was reduced from 514.313 to 348.134 . As this model covers the ten momentous factors, it will be predicted the travel behavior of wide variety of people. With the finding of this study, we can recommend some points for the further development of the sector of the public transport as follows.

Related with the characteristic of journey, travel time, travel distance and the travel cost are associated with probability to choose mode for the regular activities. Thus it is important to make some policies related with these factors. The policy makers must intervene in providing sufficient public bus services to operate and increasing frequency of buses for root with a fixed time table to provide an efficient service to the public while saving their time. On the other hand, the road passenger loading rules must be properly provides particularly for long distance trips.

Based on the factor of safety, it is important to build a communication strategy to aware people about the traffic rules and regulations while improving the road discipline of passenger and motorists to reduce the road accident. And also the city traffic regulations should be properly managed to minimized purposeful violation of traffic regulation.

Vehicle ownership is another factor that mostly influence to the mode choice for the people. Increasing vehicle ownership in Sri Lanka is also a huge problem in the transportation sector. It is impossible to make policies to control purchasing a vehicle for the purpose of private usage. Introducing some strategies such as high tax rate for purchasing vehicles and promoting park, ride, carpooling and flexible work hours etc., it can be reduced the effect from private vehicle on road and traffic congestions. On the other hand, the passenger can be encouraged to move to rail from road is a decent strategy to change the people behavior on motorization.

The perception of the traveler related to the public transport will be an essential requirement for the development of the area. As a future work of this study, it will need to capture the traveler's implicit needs and wants of the mode of the public transport by handling the concept of Kansei Engineering. 


\section{References}

Annan, J.; Mensah, J.; Boso, N. 2015. Traffic congestion Impact on Energy Consumption and Workforce Productivity: Empirical Evidence from Developing Country, Archives of Business Research, 3(4): 40-54.

Charles, E. 2014. Maximum likelihood, logistic regression, and stochastic gradient training. Available from Internet: <http://cseweb.ucsd.edu/ elkan/250B/ logreg.pdf $>$.

Cramer, D. 2003. Advanced Quantitative Data Analysis. England. McGraw-Hill Companies, Inc. USA. 122 p.

Dill, J.; Wardell, E. 1994. Factors affecting worksite mode choice findings from Portland, Oregon, Journal of the Transportation Research Board, 51-57.

Fullerton, T.M.,Jr; Walke, A.G. 2012. Border Zone Mass Transit Demand in Brownsville and Laredo, Journal of the Transportation Research Forum, 51(2): 43-59.

Hiyal, B. 2013. Income disparity rising in Sri Lanka. Available from Internet: <http://www.ceylontoday. lk/22-47092-news-detail-income-disparity-rising-insri-lanka.html>.

Jaiswal, A.A.; Sharma, A. 2012. Optimization of Public Transport Demand: A Case Study of Bhopal, International Journal of Scientific and Research Publications, 2(7): 1-16.

Japan International Cooperation Agency - JICA. 2014. CoMTrans Urban Transport Master Plan, Final Report - Japan International Copperation Agency. Japan. Available from Internet: <http://disability-studies. leeds.ac.uk/files/2011/10/DRC-transport-campaignresearch-report-October-2006.pdf $>$.

Jolly, D.; Priestley, M.; Matthews, B. 2006. Secondary analysis of existing data on disabled people's use and experiences of public transport in Great Britain, Research Report, University of Leeds.
Kumarage, A.S. 2002. Criterion for a fares policy and fares index for bus transport in Sri Lanka, International Journal of Regulation and Governance, 2(1): 53-73.

Lalitha, K.; Ruther, G.K. 2014. Road Traffic Accident, International Journal of Research in Humanities, Arts and Literature, 2(3): 83-86.

Madhuwanthi, R.A.M.; Marasignhe, A.; Janaka, P.C.; Asanka, D.D. 2015. A recommendation mechanism for the adaptation of the Activity Based Travel Demand Model. In Proceedings of the $1^{\text {st }}$ International Symposium on Affective Science and Engineering (ISASE), F2-3.

Mohammed, A.A.; Shakir, A.A. 2013. Factors that affect transport mode preference for graduate students in the national university of Malaysia by Logit Method, Journal of Engineering Science and Technology, 8(3): 351363.

Mohanty, M.; Gupta, A. 2015. Factors affecting road crash modeling, Journal of Transport Literature, 9(2): 15-19.

Niels, V.O. 2011. Service Reliability and Urban Public Transport Design, Thesis - TRAIL Thesis Series, TRAIL Research School, Netherland.

Ortuzar, J.D.; Willumsen, L.G. 1994. Modeling Transport. John Wiley \& Sons ltd. USA. 207 p.

Rasario, M. 2011. Managing urban mobility system. Emerald Group Publishing Limited, UK. 260 p.

Rundmo, T.; Nordfjærn, T.; Iversen, H.H.; Oltedal, S.; Jørgensen, S.H. 2011. The role of risk perception and other risk related judgements in transportation mode use, Safety Science, 49(2): 226-235.

Sevanatha Urban Resource Center. 2002. Sri Lanka country report - Partnership to improve access and quality of public transport - case study Colombo, Sri Lanka. WEDC, Loughborough University, UK. 
Su, F.; Schmöcker, J-D.; Bell, M.G.H. 2009. Mode Choice of Older People Before and After Shopping, Journal of Transport and Land Use, 2(1): 29-46.

Subbarao, S.S.V.; Krishna Rao, K.V. 2013. Analysis of Household activity and travel behavior: A case of Mumbai Metropolitan Region, International Journal of Emerging Technology and Advanced Engineering, 3(1): 98-109.

Sunday Times. 2001. The article - Killer Roads. Available from Internet: <http://www.sundaytimes. lk/040606/plus/1.html>.

Williams, R. 2015. Logistic Regression, Part III: Hypothesis Testing, Comparisons to OLS. Available from Internet: <https://www3.nd.edu/ rwilliam/ stats2/183.pdf $>$.

Zhan, G. 2008. Transfers and path choice in urban public transport systems, Thesis - Doctor of Philosophy, Department of Urban and Regional Planning, Massachusetts Institute of Technology.

Zhang, W.; Yue, W.L. 2001. Alternative solutions for urban traffic congestion. In Proceedings of the $3^{\text {rd }}$ Eastern Asia Society for Transportation Studies, 327-342. 